\title{
Pendampingan Manajemen Produksi Kerajinan Kayu Pada UMKM Lancar Jaya Magelang
}

\author{
Maimunah ${ }^{1, *}$, Afwan Ghiffari ${ }^{1}$, Catur Pamungkas ${ }^{1}$, Febri Kurniawan ${ }^{1}$, Padyan Farhaani ${ }^{2}$, \\ Anindita Lintang ${ }^{2}$ \\ ${ }^{1}$ Fakultas Teknik; Universitas Muhammadiyah Magelang; Jl. Mayjen Bambang Soegeng KM 5 \\ Mertoyudan Magelang Jawa Tengah,Indonesia, Telp:(0293) 326945; e-mail: \\ maimunah@ummgl.ac.id, afwanfari00@gmail.com, caturpamungkas326@gmail.com. \\ febrikurniawan149@gmail.com \\ ${ }^{2}$ Fakultas Ekonomi dan Bisnis; Universitas Muhammadiyah Magelang; Jl. Tidar No. 21 \\ Magelang, Jawa Tengah,Indonesia, (0293) 362082; e-mail: padyanfa99@gmail.com. \\ aninditalintang24@gmail.com \\ * Korespondensi: e-mail: maimunah@ummgl.ac.id
}

Submitted: 03/12/2020; Revised: 7/01/2021; Accepted: 14/01/2021; Published: 29/01/2021

\begin{abstract}
Production management is the process of planning, organizing, directing, and controlling production activities which are an important part of a business unit. Production management can also optimize a business to find out how much profit or loss an organization or business will get. Lancar Jaya is a micro, small, and medium enterprises UMKM in the field of wood crafts which is located in Pucang Village, Magelang Regency. In running its business, MSMEs Lancar Jaya still has problems in terms of management in the production section which is still carried out manually. As a result, MSMEs have difficulty in recording the procurement of raw materials to the stock of finished goods which are custom orders. The Integrated Community Service Team, University of Muhammadiyah Magelang, carries out production management assistance and also makes production management applications. With the application that has been made, it can make it easier for MSMEs in production management and can also simplify the calculation of profits.
\end{abstract}

Keywords: Community Dedication, MSME, Production Manajemen, Woodcraft

\begin{abstract}
Abstrak
Manajemen produksi adalah proses suatu perencanaan, pengorganisasian, pengarahan dan pengendalian kegiatan produksi yang menjadi bagian penting bagi suatu unit usaha. Manajemen produksi juga dapat mengoptimalkan sebuah usaha agar dapat mengetahui seberapa banyak keuntungan atau kerugian yang diperoleh suatu organisasi atau usaha. UMKM Lancar Jaya merupakan UMKM di bidang kerajinan kayu ynag berlokasi di Desa Pucang Kabupaten Magelang. Dalam menjalankan usahanya, UMKM Lancar Jaya masih mempunyai permasalahan dalam hal pengelolaan pada bagian produksi yang masih dilaksanakan secara manual. Akibatnya UMKM kesulitan dalam pencatatan pengadaan bahan baku hingga stok barang jadi yang merupakan pesanan pelanggan. Tim Pengabdian Pada Masyarakat Terpadu Universitas Muhammadiyah Magelang melaksanakan pendampingan manajemen produksi dan juga melakukan pembuatan aplikasi manajemen produksi. Dengan aplikasi yang telah dibuat maka dapat memudahkan pihak UMKM dalam manajemen produksinya dan juga dapat mempermudah dalam perhitungan keuntungan yang diperoleh.
\end{abstract}

Kata kunci: Pengabdian Masyarakat, UMKM, Manajemen Produksi, Kerajinan Kayu 


\section{Pendahuluan}

Indonesia merupakan negara yang menghasilkan banyak kerajinan-kerajinan dan terkenal baik di negara sendiri maupun di mancanegara. Jenis kerajinan yang ada di Indonesia diantaranya kerajinan kayu, kerajinan kulit, kerajinan logam, kerajinan batik dan kerajinan rotan. Telah banyak dikembangkan potensi kerajinan sesuai potensi daerahnya seperti kerajinan bambu yang diolah dalam beberapa bentuk kerajinan sesuai potensi daerahnya (Mahzuni, Z. Muhsin, \& Septiani, 2017). Produksi kerajinan kayu dipengaruhi beberapa faktor diantaranya modal, tenaga kerja dan teknologi (Deviana \& Ssudiana, 2015). Faktor - faktor tersebut berlaku secara umum untuk semua jenis kerajinan kayu termasuk jenis kerajinan ukiran kayu (Yuniartini, 2013).

Keberadaan Usaha Mikro Kecil Menengah (UMKM) sangat mendukung bagi kehidupan perekonomain khsusunya dalam pemenuhan penyediaan lapangan pekerjaan bagi masyarakat (Raharja, Putra, \& Krismawintari, 2017). UMKM Lancar Jaya merupakan salah satu UMKM yang terletak di Desa Pucang Kecamatan Secang Kabupaten Magelang yang merupakan UMKM di bidang kerajinan kayu. UMKM Lancar Jaya dibentuk ditahun 2002 dengan produk yang dihasilkan mayoritas berupa souvenir. Produk yang dihasilkan oleh UMKM Lancar Jaya merupakan produk dengan kualitas premium. Jangkauan pemasaran produk UMKM Lancar Jaya telah menjangkau di berbagai daerah di seluruh Indonesia. Namun, di sisi lain masih terdapat permasalahan di bagian produksi yaitu berkaitan dengan pengelolaan produksi. Terdapat kesulitan bagi UMKM dalam melakukan pencatatan bahan baku, stok bahan baku hingga bahan jadi, jumlah produk yang gagal, penentuan harga tiap produk hingga penghitungan keuntungan berdasarkan pembelanjaan yang telah dilakukan. Semua kegiatan tersebut masih dilakukan secara manual sehingga menyebabkan perhitungan produksi dan keuntungan menjadi kurang akurat. Hal ini yang mendorong perlunya dilakukan suatu model manajemen di bagian produksi UMKM Lancar Jaya.

Pengelolaan bagian produksi UMKM dapat juga dilakukan melalui optimalisasi proses produksi melalui pendampingan 5S, ergonomi dan K3 (Jatiningrum, Astuti, \& Utami, 2019). Beberapa model atau solusi untuk permasalahan manajemen produksi telah dilakukan diantaranya menggunakan model antrian dan simulasi untuk produksi kerajinan bambu (Nurdin \& Astuti, 2013) dan juga menggunakan statistik (Awaliyah, Mara, \& Martha, 2016). Melalui penggunaan teknologi juga dapat digunakan untuk permasalahan di sistem produksi yaitu dengan menggunakan sistem informasi manajemen yang merupakan suatu teknologi untuk permasalahan keorganisasian dalam pengolahan transaksi dan pemberian informasi bagi kepentingan organisasi. Banyak metode untuk membangun sistem informasi manajemen produksi diantaranya adalah menggunakan fuzzy logic (Pradana, Santoso, \& Eunike, 2015). Melalui optimalisasi manajemen produksi maka selanjutnya dapat dikembangkan kapasitas uasaha melalui penyusunan database dan katalog produk sehingga mendukung pemasaran UMKM (Resnawaty, Krisnani, \& Aulia, 2020). 
Universitas Muhammadiyah Magelang melalui Tim Pengabdian Pada Masyarakat Terpadu melakukan kegiatan pengabdian masyarakat di UMKM Lancar Jaya sebagai mitra. Bentuk kegiatan pengabdian masyarakat yang dialkukan berupa pendampingan manajemen produksi kerajinan kayu di UMKM Lancar Jaya. Melalui kegiatan pendampingan kegiatan pengabdian pada masyarakat maka permasalahan di UMKM dapat ditangani dan kemampuan UMKM semakin meningkat sehingga mendukung perluasan pangsa pasar UMKM (Permana, Prayudi, \& Wirahyuni, 2019).

\section{Metode Pelaksanaan}

Kegiatan PPMT ini dilaksanakan dalam beberapa tahapan seperti pada Gambar 1.

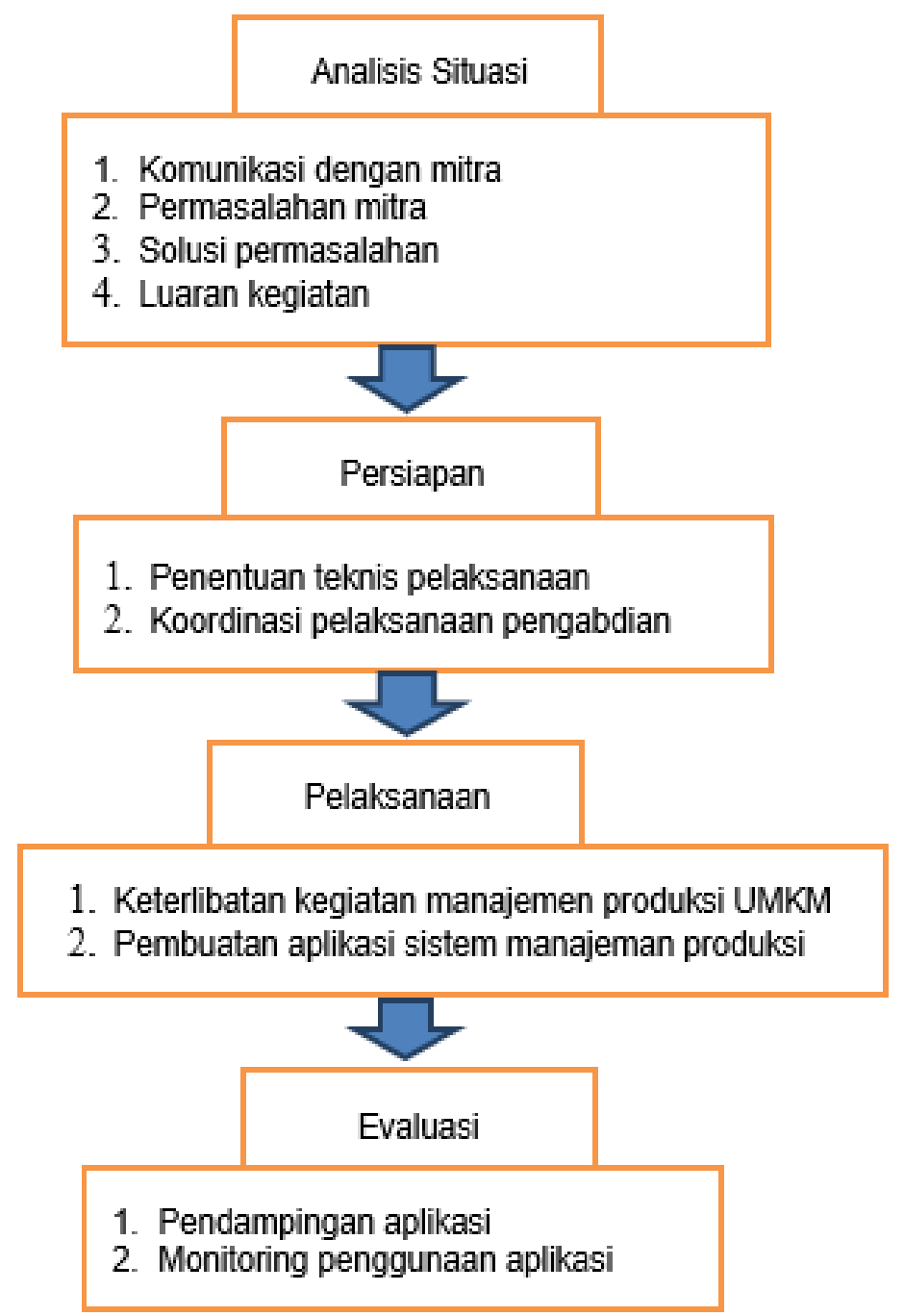

Sumber : Hasil Pelaksanaan (2020)

Gambar 1. Tahapan Pelaksanaan

Pada tahap awal kegiatan pengabdian masyarakat dilakukan analisis situasi terhadap mitra yaitu UMKM Kerajinan kayu Lancar Jaya di Desa Pucang Kabupaten Magelang. Analisis situasi dilakukan melalui komunikasi dengan mitra untuk mengetahui permasalahan yang 
dihadapi oleh mitra serta penyelesian masalah yang dapat dilakukan oleh tim pengabdian mayarakat. Selain itu, dalam tahapan ini juga ditentukan luaran kegiatan pengabdian masyarakat yang hendak dicapai yaitu aplikasi manajemen produksi UMKM Lancar Jaya. Pelaksanaan kegiatan pengabdian masyarakat dimulai melalui persiapan teknis dan koordinasi dengan pihak mitra.

Selama kegiatan pengabdian masyarakat, tim PPMT ikut terlibat dalam kegiatan produksi UMKM dari awal hingga akhir. Produksi kerajinan di UMKM Lancar Jaya dilaksanakan di 3 workshop yaitu pembahanan, penggergajian dan finishing. Lokasi workshop produksi UMKM Lancar Jaya berbeda - beda, workshop pembahanan berada di Dusun Candiretno, workshop Penggergajian berada di Dusun Gombolan dan workshop Finishing berada di Dusun Pucang.Tim PPMT terlibat dalam proses produksi mulai dari rekap bahan baku, proses pengolahan bahan baku, pencetakan bahan jadi, rekap bahan jadi hingga proses perhitungan harga bahan jadi. Keterlibatan tim PPMT dalam kegiatan produksi bertujuan untuk lebih memahami alur proses produksi sehingga dapat merancang aplikasi manajemen produksi sesuai kondisi dan kebutuhan UMKM. Pembuatan aplikasi dilakukan seiring dengan kegiatan di bagian produksi UMKM. Aplikasi yang telah selesai dibuat selanjutnya disosialisasikan ke pihak mitra sekaligus pendampingan dan monitoring penggunaan aplikasi.

\section{Hasil Pembahasan}

Lancar Jaya Handycraft merupakan salah satu UMKM yang berada di Desa Pucang Kecamatan Secang yang didirikan oleh Bapak Fatkur Rozaq pada tahun 2002 silam dengan jumlah pegawai sebanyak 50 orang. UMKM ini mengolah kayu menjadi bahan kerajinan seperti alat rumah tangga dan souvenir. Kerajinan kayu merupakan salah satu bentuk kreativitas dalam membuat sebuah desain atau seni, serta menjadikan produk tersebut bernilai seni dan jual yang tinggi. Pada tahap awal kegiatan PPMT dilakukan komunikasi dengan mitra yaitu dengan pihak mitra UMKM Lancar Jaya. Dalam kegiatan ini dilakukan pembahasan mengenai permasalah mitra, penyelesaian permasalahan, teknis kegiatan pengabdian dan koordinasi kegiatan pengabdian seperti disajikan dalam Gambar 2. Permasalahan utama dari produksi di UMKM Lancar Jaya adalah pencatatan yang masih manual sehingga menyebabkan kehilangan data, kesulitan melakukan pengawasan terhadap stok bahan baku dan bahan jadi serta penentuan harga jual produk yang lebih akurat berdasarkan biaya produksi. Untuk mendukung analisa kebutuhan yang diperlukan dalam pembuatan aplikasi maka Tim PPMT terlibat langsung dalam kegiatan proses produksi di workshop UMKM Lancar Jaya. Melalui keterlibatan langsung tersebut diharapkan dapat lebih memahami alur pengelolaan produksi di UMKM sehingga lebih memudahkan dalam pembuatan aplikasinya. 


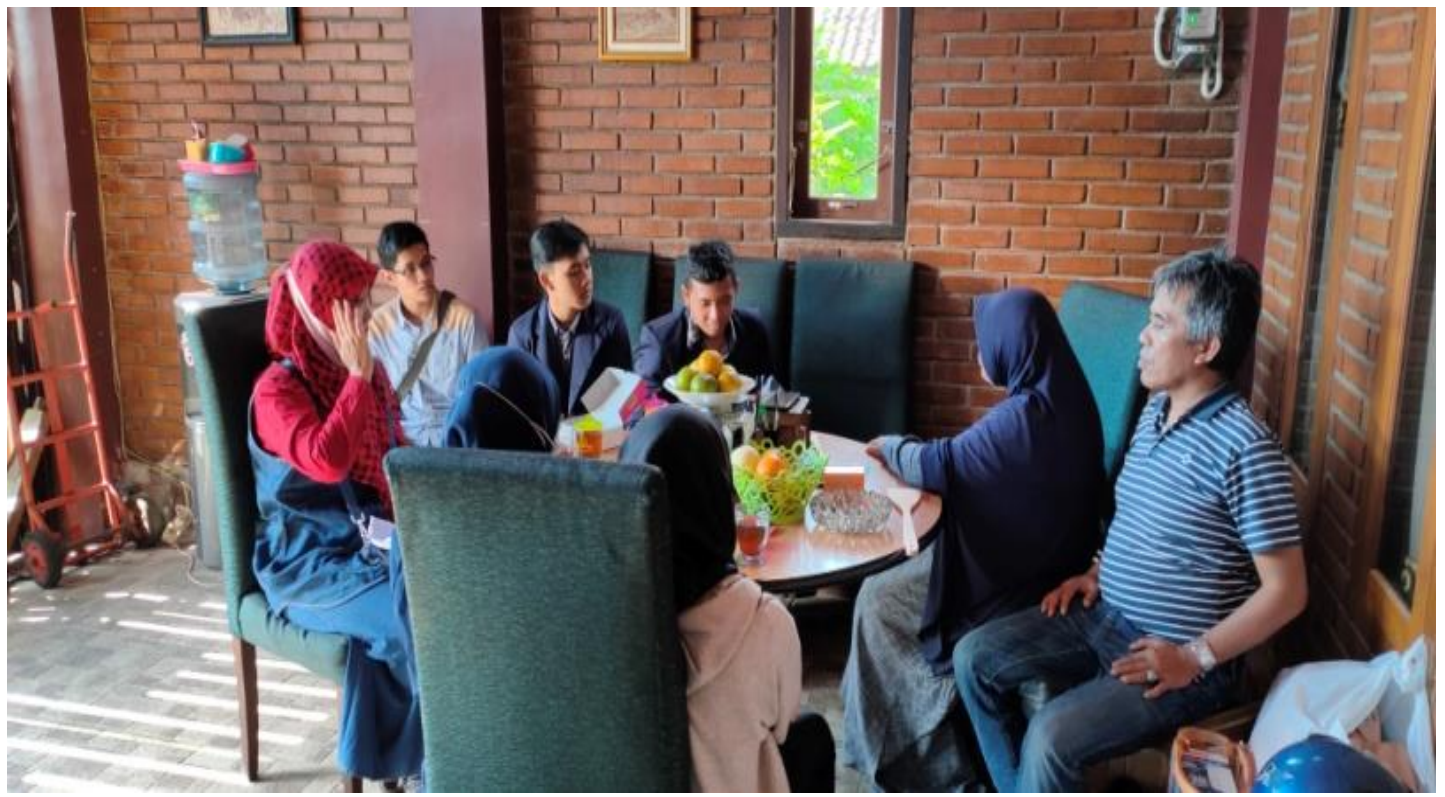

Sumber : Hasil Pelaksanaan (2020)

Gambar 2. Koordinasi Dan Persiapan Kegiatan

Pencatatan yang dilakukan di UKM Lancar Jaya masih dilakukan secara manual, seperti ditunjukkan pada Gambar 3.

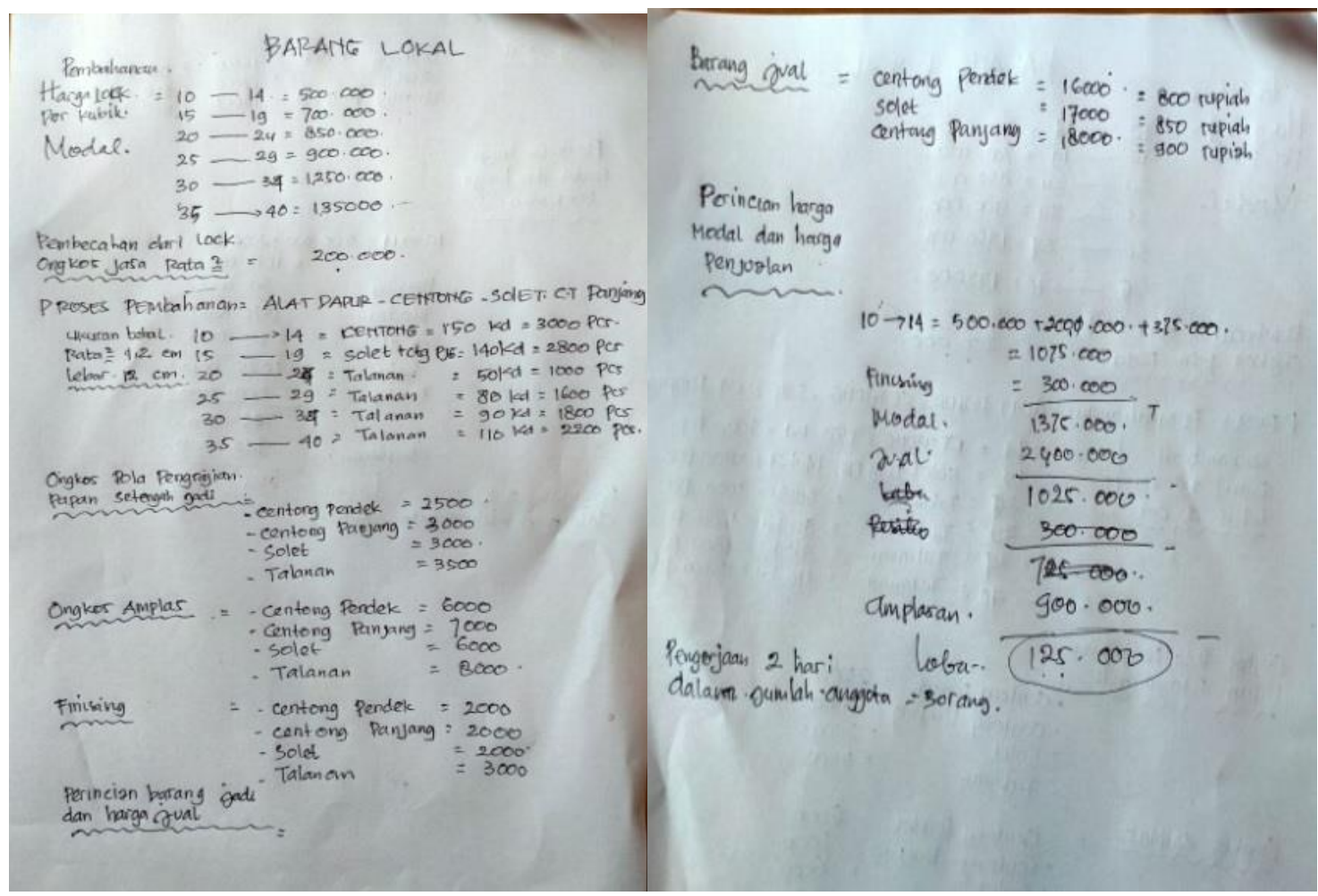

Sumber : Hasil Pelaksanaan (2020)

Gambar 3. Pencatatan Manual di UMKM Lancar Jaya 
Dalam pembuatan aplikasi maka Tim PPMT terlibat langsung dalam kegiatan proses produksi di workshop UMKM Lancar Jaya, seperti ditunjukkan pada gambar 4.

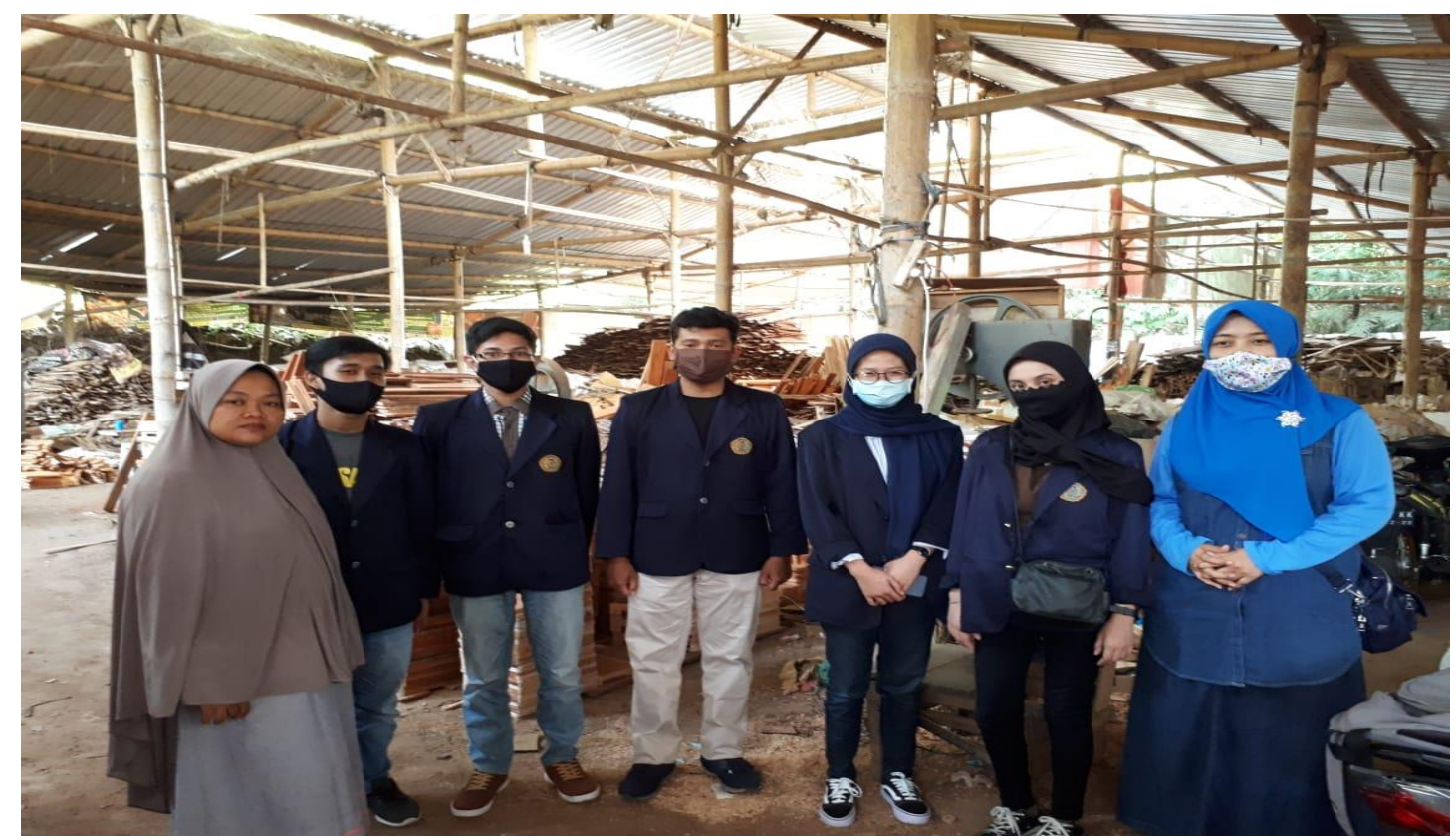

Sumber : Hasil Pelaksanaan (2020)

Gambar 4. Kegiatan Workshop Pembahanan UMKM Lancar Jaya

Untuk mengetahui analisa kebutuhan dari aplikasi manajemen produksi yang dirancang maka Tim PPMT ikut terlibat dalam proses produksi kerajinan kayu. Proses produksi di UMKM Lancar Jaya Handycraft dilakukan di tiga workshop yang berbeda yang terdiri dari Workshop Pembahanan, Workshop Penggergajian dan Workshop Finishing. Untuk Workshop Pembahanan berada di dusun Candiretno dengan jumlah pegawai 8 orang. Workshop Penggergajian dikerjakan di dusun Gombolan jumlah pegawai 20 orang dan Workshop Finishing berada di dusun Pucang dengan jumlah pegawai 20 orang.

Sistem manajemen produksi UMKM Lancar Jaya dirancang untuk pengelolaan produksi yang terdiri dari 3 workshop. Mayoritas produksi di UMKM adalah produksi pesanan dari pelanggan. Dalam aplikasi yang dibuat meliputi pencatatan di workshop pembahanan hingga pencatatan pesanan pelanggan. Pencatatan di menu pembahanan dilakukan mulai bahan baku datang, jenis dan ukuran bahan baku, volume hingga penentuan harga. Tampilan menu pembahanan seperti pada Gambar 5. Selain menu pembahanan pada aplikasi ini juga terdapat menu produksi dan menu histori yang bermanfaat untuk memudahkan dalam merekap data pelanggan. 


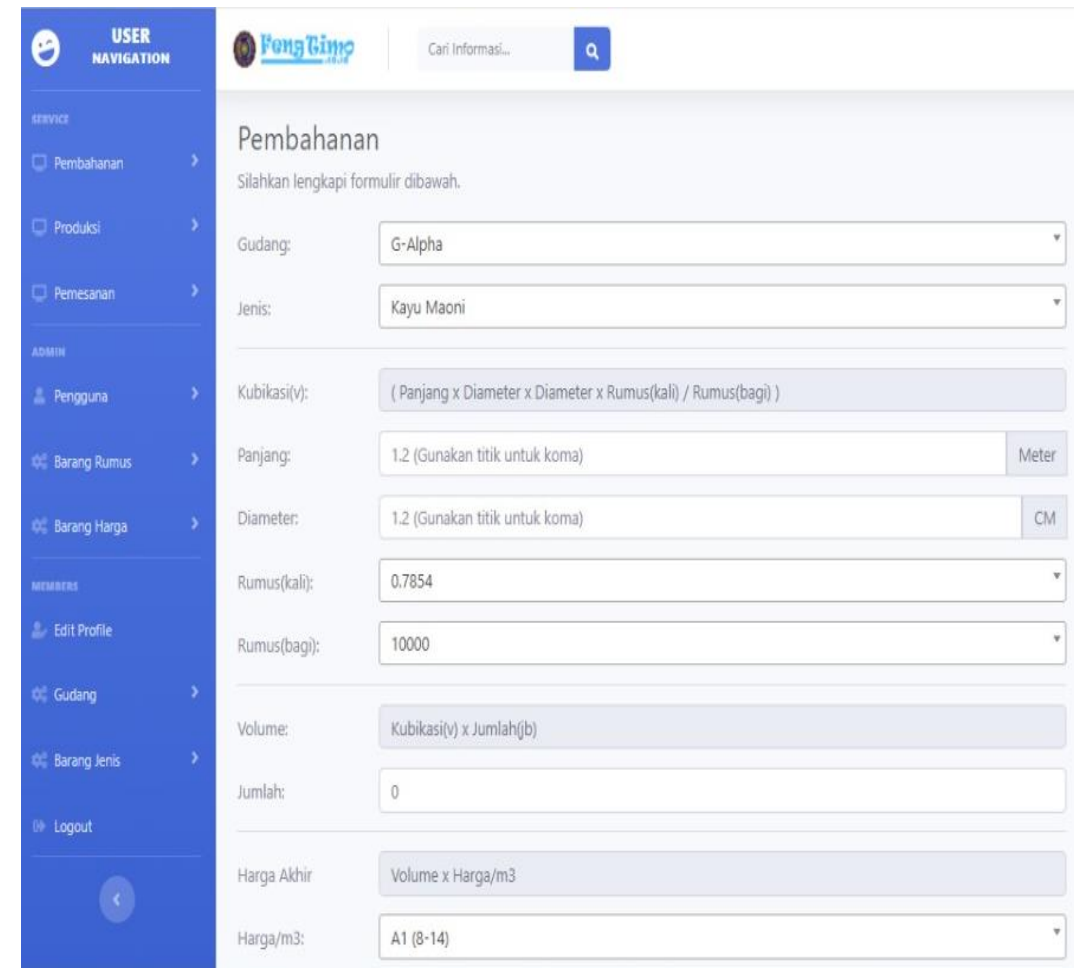

Sumber : Hasil Pelaksanaan (2020)

Gambar 5. Tampilan Menu Pembahanan

Pada menu produksi dilakukan pencatatan jenis bahan baku yang digunakan, jenis produk yang hendak dibuat, ukuran, jumlah unit, batas waktu pembuatan dan sumber order. Tampilan menu produksi seperti pada Gambar 6.

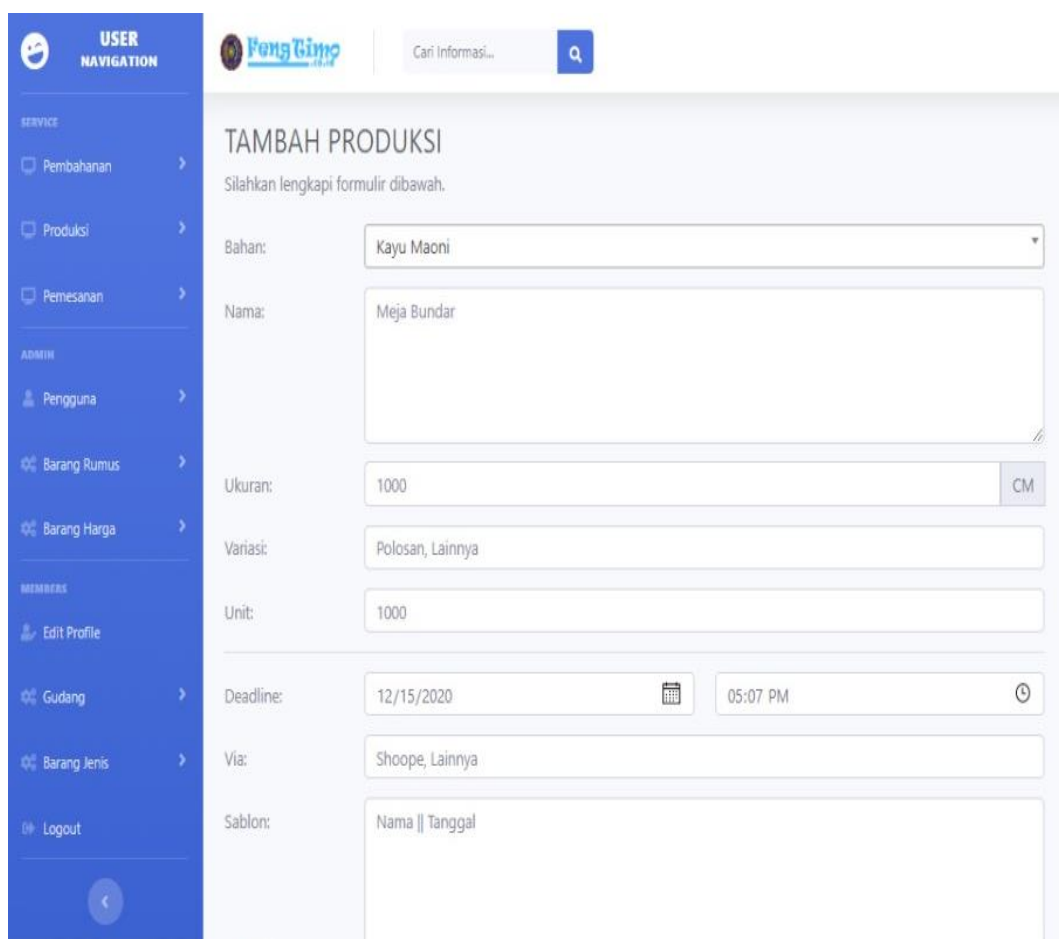

Sumber : Hasil Pelaksanaan (2020)

Gambar 6. Tampilan menu produksi 
Selain itu juga terdapat menu histori pemesanan untuk memudahkan dalam merekap data pelanggan, seperti yang disajikan dalam Gambar 7 .

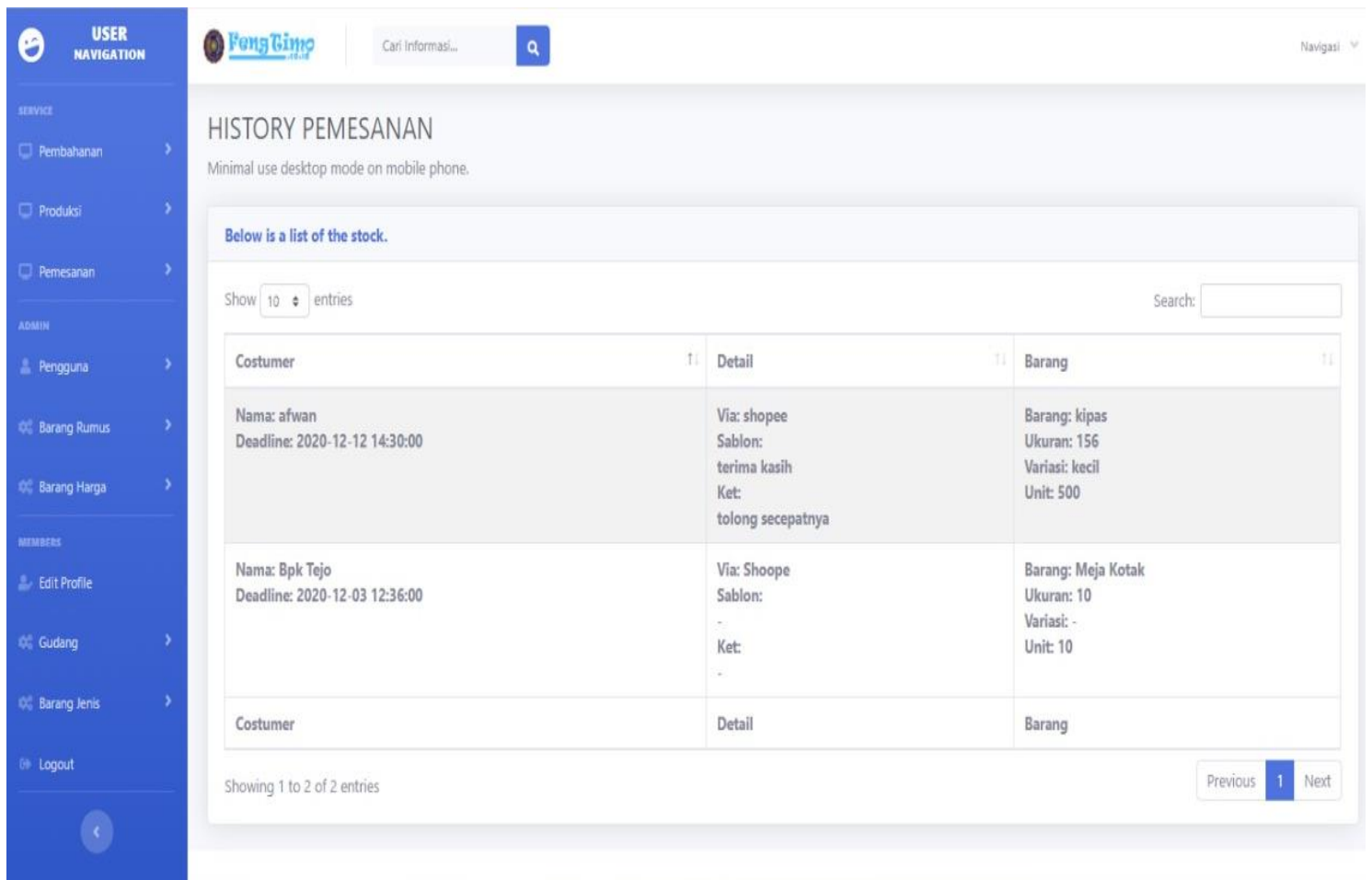

Sumber : Hasil Pelaksanaan (2020)

Gambar 7. Tampilan menu history pemesanan

Aplikasi yang telah dibuat selanjutnya dilakukan sosialisasi dan pendampingan terhadap mitra yang bertujuan untuk memudahkan mitra dalam penggunaan aplikasi. Pihak UMKM langsung mempraktekan pencatatan produksi hingga semua layanan di aplikasi dipahami oleh pengguna. Pendampingan aplikasi dilakukan oleh Tim PPMT seperti disajikan dalam Gambar 8.
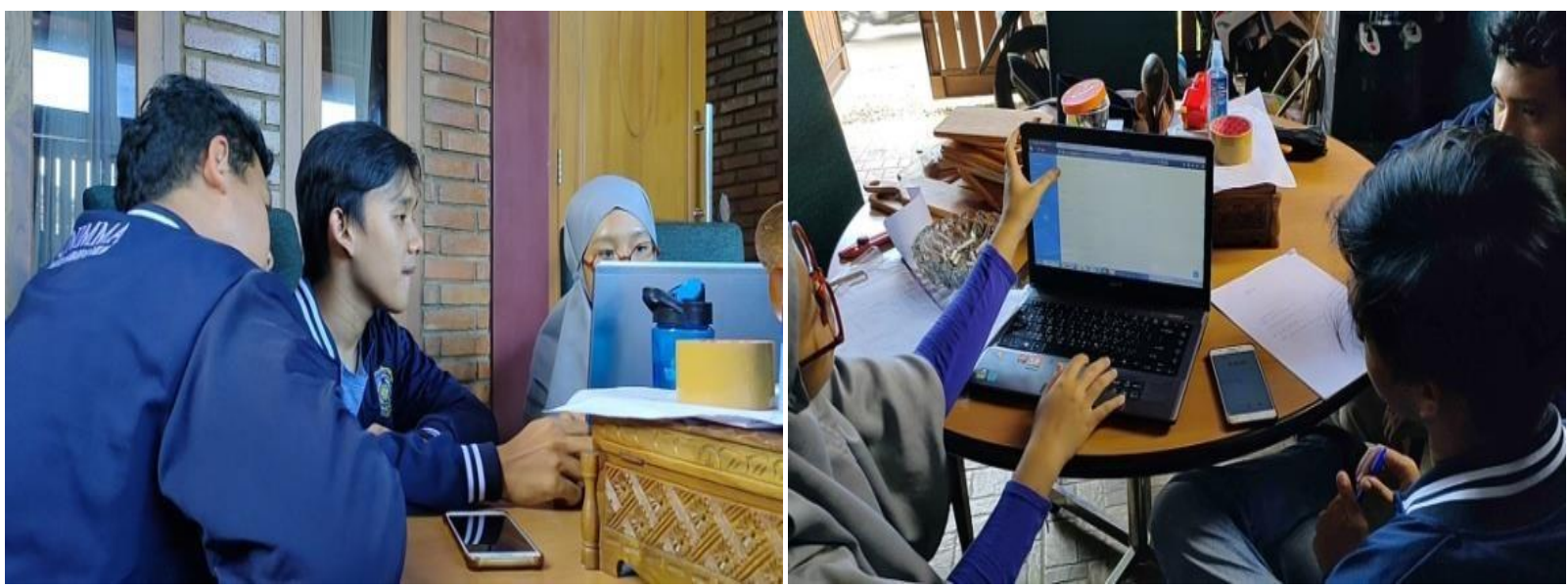

Sumber : Hasil Pelaksanaan (2020)

Gambar 8. Pendampingan penggunaan aplikasi 


\section{Kesimpulan}

Kegiatan dari pengabdian masyarakat yang telah dilakukan Tim PPMT di UMKM Lancar Jaya berfokus pada manajemen produksi. Luaran dari kegiatan ini berupa aplikasi sistem manajemen produksi yang bertujuan untuk mempermudah pengelolaan di bagian produksi UMKM Lancar Jaya. Melalui aplikasi yang telah dibuat maka dapat memudahkan pihak UMKM dalam pencatatan mulai dari pengadaan bahan baku hingga bahan jadi sesuai yang telah dipesan oleh pelanggan serta memudahkan dalam perhitungan keuntungan yang diperoleh.

\section{Ucapan Terima Kasih}

Tim Pengabdian Pada Masyarakat Terpadu (PPMT) Universitas Muhammadiyah Magelang mengucapkan terima kasih kepada mitra yaitu UMKM Lancar Jaya yang telah bersedia menjadi mitra dalam pengabdian masyarakat ini. Semoga apa yang telah dilakukan dapat memberikan manfaat bagi kedua belah pihak.

\section{Daftar Pustaka}

Awaliyah, Mara, M. N., \& Martha, S. (2016). Analisis Produksi Kayu Lapis Menggunakan Statistical Quality Control. Buletin IImiah Mat. Stat. Dan Terapannya (Bimaster), 05(1), 18.

Deviana, M. L., \& Sudiana, I. K. (2015). Pengaruh Beberapa Faktor Terhadap Produksi Industri Kerajinan Kayu di Abiansemal. E-Jurnal Ekonomi Pembangunan Universitas Udayana, 4(7), 811-827.

Jatiningrum, W. S., Astuti, F. H., \& Utami, E. (2019). Pendampingan Proses Produksi Kerajinan Kayu UMKM Tunas Karya Dusun Gumawang Kecamatan Patuk Kabupaten Gunung Kidul. Seminar Nasional Hasil Pengabdian Kepada Masyarakat Universitas Ahmad Dahlan, (September), 41-48.

Mahzuni, D., Z. Muhsin, M., \& Septiani, A. (2017). Pengembangan Kerajinan Tangan Berbasis Kearifan Budaya di Pakenjeng Kabupaten Garut. Dharmakarya: Jurnal Aplikasi Ipteks Untuk Masyarakat, 6(2), 101-105.

Nurdin, R., \& Astuti, M. (2013). Pengembangan Model Work in Process Pada Ukm Produk Kerajinan Bambu Dengan Pendekatan Metode Antrian Dan Simulasi. ANGKASA, V(2), 133-142.

Permana, A. A. J., Prayudi, M. A., \& Wirahyuni, K. (2019). Program Kemitraan Masyarakat UMKM Kerajinan Kayu (Bowl dan Bokor) di Kecamatan Buleleng, Singaraja-Bali. Prosiding Seminar Nasional Pengabdian Kepada Masyarakat (SENADIMAS) 4, 140-148.

Pradana, A. C., Santoso, P. B., \& Eunike, A. (2015). Perancangan Sistem Informasi Manajemen Produksi Dengan Pemanfaatan Pendekatan Fuzzy Logic Untuk Penentuan Jumlah Produksi. Jurnal Rekayasa Dan Manajemen Sistem Industri, 3(1), 154-165.

Raharja, M. A., Putra, I. M. W. A., \& Krismawintari, N. P. D. (2017). Peningkatan dan Pengembangan Produksi Usaha Kerajinan Kayu Berbasis Teknologi Tepat Guna di Desa 
Petulu Kecataman Ubud Gianyar. Paradharma (Jurnal Aplikasi IPTEK), 1(1), 17-22.

Resnawaty, R., Krisnani, H., \& Aulia, R. M. (2020). Pengembangan Kapasitas Usaha Kecil/Menengah Kerajinan Kayu Cipacing MelaluiPenyusunan Database dan Katalog. Kumawula: Jurnal Pengabdian Kepada Masyarakat, 3(2), 163-173. https://doi.org/10.24198/jppm.v7i1.25338

Yuniartini, N. (2013). Pengaruh Modal, Tenaga Kerja Dan Teknologi Terhadap Produksi Industri Kerajinan Ukiran Kayu Di Kecamatan Ubud. E-Jurnal Ekonomi Pembangunan Universitas Udayana, 2(2), 95-101. 